Viso - Cadernos de estética aplicada Revista eletrônica de estética

ISSN 1981-4062

$N^{\circ} 2$, mai-ago/2007

http://www.revistaviso.com.br/

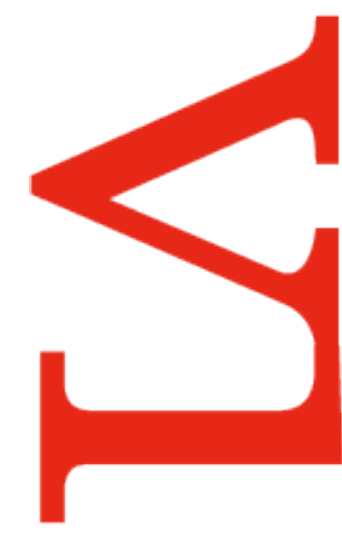

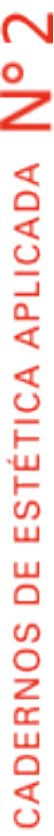
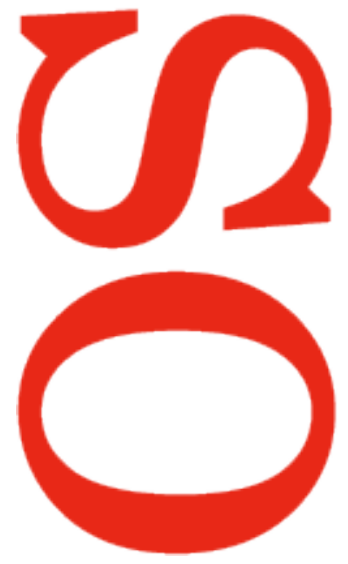

\title{
Poesia em tempos de indigência
} Pedro Süssekind 


\section{RESUMO}

\section{Poesia em tempos de indigência}

O artigo a seguir discute as conexões entre o filme Quei loro incontri, de Jean-Marie Straub, o romance Diálogos com Leucó, de Cesare Pavese, e as reflexões de Friedrich Hölderlin acerca da Grécia Clássica, dos deuses e do mundo moderno. A célebre pergunta "Para que poetas em tempos de indigência?", do poema "Pão e vinho" de Hölderlin, serve como referência para essa discussão.

\section{Palavras-chave:}

estética alemã - cinema - literatura - Hölderlin - Pavese - Straub

\section{ABSTRACT}

\section{Poetry in times of need}

The following text discusses the connections between Jean-Marie Straub's movie Quei Ioro incontri, Cesare Pavese's novel Dialogues with Leuco and Friedrich Hölderlin's ideas about the Greeks, the gods and the modern world. The famous question "What use are poets in times of need", from Hölderlin's poem "Bread and wine", is a reference for this discussion.

\section{Keywords:}

German aesthetics - cinema - literature - Hölderlin - Pavese - Straub 
SÜSSEKIND, P. "Poesia em tempos de indigência". In: Viso: Cadernos de estética aplicada, v. I, n. 2 (mai-ago/ 2007), pp. 28-37.

DOI: $10.22409 / 1981-4062 / v 2 i / 38$

Aprovado: 11.06.2007. Publicado: 12.08.2007.

(C) 2007 Pedro Süssekind. Esse documento é distribuído nos termos da licença Creative Commons Atribuição-NãoComercial 4.0 Internacional (CC-BY-NC), que permite, exceto para fins comerciais, copiar e redistribuir o material em qualquer formato ou meio, bem como remixá-lo, transformá-lo ou criar a partir dele, desde que seja dado o devido crédito e indicada a licença sob a qual ele foi originalmente publicado.

Licença: http://creativecommons.org/licenses/by-nc/4.0/deed.pt_BR

Accepted: 11.06.2007. Published: 12.08.2007.

(C) 2007 Pedro Süssekind. This document is distributed under the terms of a Creative Commons Attribution-NonCommercial 4.0 International license (CC-BY-NC) which allows, except for commercial purposes, to copy and redistribute the material in any medium or format and to remix, transform, and build upon the material, provided the original work is properly cited and states its license.

License: http://creativecommons.org/licenses/by-nc/4.0/ 
Quando o último filme do casal de cineastas Daniele Huillet e Jean-Marie Straub, intitulado Quei loro incontri, foi exibido na mostra competitiva do Festival de Veneza em 2006, mais da metade das pessoas que lotavam a Sala Grande do Festival abandonou a sessão, a maior parte durante os primeiros dez ou vinte minutos. O nome "Quei loro incontri", em português "Aqueles encontros com eles", é uma citação da última frase do livro Diálogos com Leucó, de Cesare Pavese, do qual Straub já tinha adaptado alguns trechos num filme anterior (Das Nuvens à Resistência, 1979). Na nova adaptação, de 2006, o diretor transpôs para o cinema cinco dos "diálogos" indicados no título, de uma maneira muito própria e bastante desconcertante, que mantém as características formais de sua filmografia anterior e explica o estranhamento do público, acostumado à ação constante e muitas vezes vertiginosa da linguagem cinematográfica.

A adaptação funciona assim: cada diálogo é simplesmente recitado por atores que, parados numa determinada posição, encontram-se em lugares ermos, como o alto de uma montanha, a beira de um riacho ou a sombra de uma floresta. Nas cinco seqüências, de aproximadamente dez minutos cada, sempre com dois atores em cena dialogando, de raro em raro há apenas uma leve mudança de posição do corpo no decorrer da recitação do texto. Em enquadramentos igualmente estáticos (ou quase, pois às vezes é feito também um movimento de câmera), os atores vestidos com roupas simples de camponeses falam virados para os lugares ermos da paisagem. Em 68 minutos de duração, as seqüências de recitação de um texto literário apresentam pouco mais de sessenta planos, o que resulta num ritmo extremamente lento e monótono.

Uma declaração do diretor pode esclarecer sua intenção e a reação que ela desperta: "Infelizmente, o cinema é uma linguagem, mas tento destruir esta linguagem, tento fazer filmes que não levem em consideração esta linguagem". ${ }^{1}$ A conseqüência dessa intenção é uma forma de fazer cinema que simplesmente descarta as convenções e os pressupostos da linguagem cinematográfica.

Complementando a declaração de Straub, Daniele Huillet explica:

Não é nada complicado: é o mesmo trabalho que fazem os poetas sobre a língua. Eles pegam uma língua que em muitos casos tornou-se rígida, tornou-se um sistema de hábitos que é quase uma língua morta e bruscamente tentam fazer coisas que ainda não foram feitas ou que foram esquecidas há muito tempo. ${ }^{2}$

A esse propósito de desconstrução e reorganização da linguagem formal do cinema, comparado com o trabalho dos poetas, corresponde um conteúdo igualmente poético, que pode ser exemplificado pela produção anterior dos cineastas. Ela inclui, por exemplo, A morte de Empédocles (1987), uma adaptação da tragédia de Hölderlin, e Antígona (1991), baseado tanto na tragédia clássica de Sófocles quanto em sua tradução pelo poeta alemão. Desse modo, ao escolher os Diálogos com Leucó para adaptar, Straub voltava às mesmas questões poéticas que já tinha elaborado outras vezes e que se refletem em sua forma de fazer filmes. 
Assim como sua versão para o cinema, o livro de Pavese também foi recebido com estranhamento pelo público na época de sua publicação (1947), marcada pelo engajamento na literatura européia. Os críticos reagiram com surpresa ao fato de um autor ligado ao Novo Realismo, identificado como um intelectual comprometido com a esquerda, ter tomado um caminho tão "idealista" e "romântico" ao escolher temas clássicos, recorrer a personagens da Antigüidade e discutir questões metafísicas. Admirador declarado de Thomas Mann, especialmente de José e seus irmãos, Pavese decidira explorar a seu modo o território do mito em seus Diálogos com Leucó, que começaram a ser redigidos durante a Segunda Guerra Mundial. Ao comentar a mudança de sua literatura, o escritor menciona "um novo aspecto de seu temperamento", para o qual contribuía a lembrança dos clássicos lidos na escola e também uma "fase lunática", movida por uma "musa oculta". ${ }^{3}$

Os vinte e sete diálogos que compõem o livro têm como interlocutores personagens da mitologia grega, por exemplo Prometeu e Hércules, Dionísio e Deméter, um sátiro e uma ninfa, o poeta Hesíodo e Mnemósine, a mãe das musas. Esses personagens conversam sobre o destino dos homens e dos deuses, sobre os mistérios, sobre a mortalidade e a imortalidade, sobre a natureza e a poesia. Na elaboração dessas questões, como afirma Ítalo Calvino num ensaio sobre o escritor, "Pavese nos solicita para um modo de leitura que infelizmente a literatura contemporânea nos proporciona cada vez mais raramente: isto é, ele deseja ser lido como se lêem os grandes trágicos...." ${ }^{4}$

A observação de Calvino pode indicar o parentesco da obra de Pavese com as idéias ligadas ao movimento romântico alemão, especialmente a Hölderlin, um poeta que também desejava ser lido "como se lêem os grandes trágicos". De fato, Diálogos com Leucó retoma uma questão fundamental da filosofia do trágico elaborada por Hölderlin: o afastamento dos deuses ou, na terminologia própria do poeta alemão, "o afastamento categórico". Esse tema foi desenvolvido por Hölderlin tanto em suas obras literárias, como o poema "Os deuses andavam outrora", o romance Hipérion ou o eremita na Grécia, a tragédia A morte de Empédocles e as traduções de Édipo e Antígona, quanto em seus ensaios teóricos sobre essas obras, como o "Fundamento para Empédocles", as "Observações sobre Antígona" e as "Observações sobre Édipo".

A definição do afastamento categórico, nesse último texto ("Observações sobre Édipo"), é certamente uma das formulações mais enigmáticas e difíceis de compreender da história da filosofia ou da literatura. Referindo-se à tragédia de Édipo, Hölderlin fala de um "tempo inoperante", em meio à peste e à confusão de sentido, fala de um "limite extremo do sofrimento humano", que leva ao esquecimento dos deuses, fala também de um afastamento dos deuses em relação aos homens, de uma "infidelidade divina". ${ }^{5}$

Esse mesmo tema pode ser definido segundo os versos do poema "Pão e vinho", no qual Hölderlin elabora tanto a relação de esquecimento dos homens com os deuses, quanto o afastamento dos deuses em relação aos homens. Há, em primeiro lugar, uma incapacidade de reconhecimento do âmbito divino, imposta pelas limitações humanas: 
Assim é o homem: quando um bem se apresenta e um deus lhe traz

As suas dádivas, não o reconhece nem o vê.

Tem antes de sofrer para dar nome ao que lhe é mais caro;

Aí sim, as palavras lhe virão como vêm as flores. ${ }^{6}$

Em seguida, define-se a atitude dos próprios deuses, que se tornaram indiferentes ao que fazem os homens:

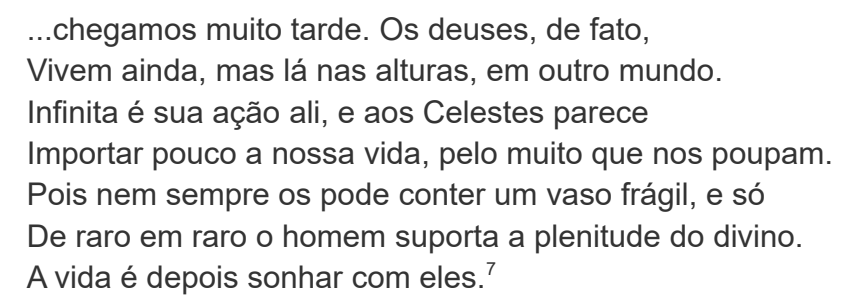

Sonhar com os deuses, no poema "Pão e vinho", é uma metáfora para a atividade do poeta. A experiência do divino descrita por Hölderlin nada mais é do que a experiência da poesia, de uma embriaguez da palavra transbordante, de um olhar para a natureza que enxerga, nela, o mistério, o sagrado, a força criativa, os signos e os significados dignos de serem cantados. Nessa concepção, a poesia é a celebração de uma experiência única, de uma capacidade de ver as coisas como se fosse pela primeira vez, como se fosse no exato instante de seu surgimento e como se a palavra ressoasse a riqueza e a complexidade desse olhar. Por isso, na época em que os homens esquecem os deuses e os deuses se afastam dos homens, haveria uma pobreza poética, uma indigência de signos e sentidos na falta da experiência do divino. É nesse contexto que aparece a célebre pergunta feita por Hölderlin: "para que poetas em tempo de indigência?". ${ }^{8}$

Diálogos com Leucó fala dessa mesma experiência do divino tematizada no poema alemão do século XIX, e a referência também é o mito grego, a experiência dos deuses descrita nas tragédias antigas. Alguns diálogos retomam diretamente a situação de uma tragédia, como acontece por exemplo no texto "O penhasco", em que Hércules conversa com Prometeu, numa versão do encontro elaborado por Ésquilo em Prometeu acorrentado. O tema principal desse diálogo é o saber, anunciado pelo titã ao herói, de que há um tempo anterior e um tempo posterior aos deuses, ou seja, os deuses nasceram e vão desaparecer. Prometeu diz a Hércules: "existe uma sabedoria mais antiga. O mundo é velho, mais do que este rochedo. E também eles o sabem. Cada coisa tem um destino. Mas os deuses são jovens, quase tão jovens quanto você". 9

A caracterização do tempo anterior à lei imposta pelos deuses olímpicos, como um ordenamento do mundo, associa o titânico às forças da natureza, à mera existência das coisas insensíveis e silenciosas. "Não é o mundo dos monstros e do caos?" - pergunta Hércules. E Prometeu responde: 
Dos titãs e dos homens, Hércules. Das feras e dos bosques. Do mar e do céu. É o mundo da luta e do sangue, que fez de você o que é. Até o último deus, o mais iníquo, era então um titã. Não há coisa que permaneça, no mundo presente ou futuro, que não fosse titânica. ${ }^{10}$

Definindo a concretude silenciosa desse passado titânico, anterior aos deuses, Hércules afirma: "Era um mundo de pedras". ${ }^{11}$

Numa versão do afastamento caracterizado por Hölderlin, o Prometeu de Pavese prevê também o desaparecimento dos deuses: "A morte entrou neste mundo junto com os deuses. Vocês mortais temem a morte porque sabem que, como tais, os deuses são imortais. Mas cada um tem a morte que merece. Também eles perecerão". ${ }^{12}$

A pergunta que fica então é: o que restará após a morte dos deuses? Nessa pergunta, que ressoa em vários trechos do livro de Pavese, talvez se possa identificar a perspectiva e a intenção de sua retomada do tema "romântico" e da filosofia do trágico. Pois se Hölderlin questionava a tragédia moderna em sua relação problemática com a antiga (e com isso pensava tanto o trágico quanto o moderno), Pavese remete $\mathrm{o}$ desaparecimento dos deuses a uma reflexão sobre futuro da humanidade. Escrevendo durante a Segunda Guerra, ele põe na boca de seus personagens previsões relativas ao domínio técnico de forças naturais e ao uso destrutivo ou construtivo dessas forças por parte dos homens.

Assim, embora as questões discutidas por Pavese pareçam muito distantes das preocupações realistas de sua época, esse tema talvez revele uma atualidade justamente pela distância, indicando o foco da leitura que pode ser feita hoje em dia. Porque atualmente não existem mais ermos, todos os cumes das montanhas e beiras dos rios e interiores de florestas já foram explorados e ocupados, praticamente não existem lugares solitários em que a influência direta do homem passe despercebida. Hoje, quando se discute se o efeito da atividade humana sobre o planeta destruirá definitivamente ou não a natureza tal como a conhecemos, até a lembrança de uma experiência do divino ligada ao âmbito natural parece fugidia. Simbolizando a relação muito pouco poética do homem com a natureza, essa discussão poderia revelar a dimensão titânica assumida pelo homem após o "afastamento dos deuses". Como diz Prometeu, no diálogo de Pavese, "o mundo tem estações, como os campos e a terra. Retorna o inverno, retorna o verão. Quem pode dizer que a selva há de perecer? Ou que perdure? Vocês serão os titãs, dentro em breve". ${ }^{13}$

No entanto, apesar dessa diferença de perspectiva entre o tempo de Pavese e o de Hölderlin, assim como nos textos do poeta alemão também no livro do escritor italiano a relação com o divino diz respeito à experiência poética. Essa referência é abordada em vários dos Diálogos, quase sempre sob a perspectiva dos próprios deuses ou de criaturas mitológicas. Por exemplo, no diálogo "O mistério", o deus do vinho Dioniso comenta: "Os mortais são divertidos. Sabemos as coisas, e eles as fazem. Sem eles, me 
pergunto o que seriam os dias. O que seríamos nós olímpicos. Chamam-nos com suas vozinhas e nos dão nomes". ${ }^{14}$ Fica indicada assim a associação do tema da relação entre homens e deuses com a experiência da linguagem e da poesia.

É ainda Dioniso que, desenvolvendo essa associação, afirma: os homens "têm um modo de nomear a si próprios e às coisas e a nós que enriquece a vida. [...] Onde quer que espalhem trabalhos e palavras, nasce um ritmo, um sentido, um repouso". E seu interlocutor, Deméter, deus do trigo e do cultivo da terra, complementa: "E as histórias que contam sobre nós? [...] Sabem dar nomes que nos revelam a nós próprios, laco, e nos arrancam da pesada eternidade do destino para nos colorir nos dias e nas aldeias por onde andamos". ${ }^{15}$

Depois de ser indicado nessas falas dos deuses do pão e do vinho (o que nos remete de novo ao poema de Hölderlin), o tema da poesia é abordado diretamente no diálogo entre Hesíodo e Mnemósine, intitulado "As musas". Na conversa entre o poeta e a personificação mítica da memória, Pavese descreve a transformação da vida banal em modelo, o encontro com as coisas sem o tédio cotidiano, como se elas fossem vistas pela primeira vez.

Especulando sobre a maneira de ver da divindade com a qual dialoga, Hesíodo afirma para Mnemósine: "As coisas que você diz não trazem em si o tédio daquilo que acontece todos os dias. Você dá às coisas uns nomes que as tornam diferentes, inéditas, ao mesmo tempo queridas e familiares como uma voz que silenciava há tempos...". ${ }^{16}$ Ao ouvir o comentário do poeta, a mãe das musas lhe pergunta se ele já sentiu a mesma coisa, se já enxergou uma planta, uma pedra, um gesto dessa maneira inédita e única que o próprio Hesíodo atribui aos deuses.

A resposta do poeta é afirmativa, mas traz um lamento, pois na perspectiva humana essa visão das coisas destituída de todo tédio do já visto é "apenas um instante", que não pode ser detido. Mnemósine descreve então a experiência poética:

Não se perguntou por que um átimo, semelhante a tantos do passado, deve fazê-lo de repente feliz, feliz feito um deus? Você observava a oliveira, a oliveira na trilha que percorre todos os dias durante anos, e chega o dia em que o tédio o deixa e você acaricia o velho tronco com o olhar, como se fosse um amigo reencontrado e the dissesse exatamente a única palavra que seu coração esperava. Outras vezes é o olhar de um passante qualquer. Outras vezes a chuva que insiste dias seguidos. Ou a voz estrepitosa de uma ave. Ou uma nuvem que lhe parece já ter visto. Por um instante o tempo se detém, e a coisa banal, você a sente no coração como se o antes e o depois não existissem mais. Não perguntou o porquê? ${ }^{17}$

O poeta sabe o porquê, e sua resposta define a relação que ele estabelece com a memória: "aquele instante tornou a coisa uma lembrança, um modelo". É justamente a partir desse saber, ou seja, da própria relação entre Hesíodo e Mnemósine, que a própria divindade mostra a maneira de compreender o divino. Ela pergunta: "Não consegue pensar uma existência inteiramente feita desses instantes?". A resposta mais uma vez é 
afirmativa: "Claro que sim". E Mnemósine conclui: "Então sabe como vivo. [...] Sabe o que é a vida imortal". ${ }^{18}$

A mãe das musas ensina ao poeta que a vida imortal, a maneira de ver de uma divindade é uma existência inteiramente feita desses instantes poéticos, que para os homens são fugidios e passageiros. Em outras palavras, isso mesmo que o poeta experimenta raramente, como um instante fugidio que ele procura apreender, é a maneira como a divindade vive por toda a eternidade. Assim, a tarefa do poeta é anunciada ao final do diálogo: dizer o que sabe, dizer o que é o divino, dizer o que vê, o instante destituído de tédio em que as coisa aparecem como se fossem vistas pela primeira vez, no frescor desse encontro que as transforma num modelo e no qual elas contêm "a única palavra" que o coração espera. Como no contexto de desenvolvimento do Romantismo alemão, o poeta aqui é uma espécie de "guardião da natureza". ${ }^{19} \mathrm{E}$, como no pensamento de Hölderlin, mesmo em tempos de indigência cabe aos poetas descrever o encontro com a natureza, que tem a capacidade de se transformar em encontro com o divino.

O último diálogo do livro de Pavese é o único cujos participantes não são deuses nem personagens do mito grego, mas homens, cujas falas revelam que estão situados num lugar solitário, num ermo cercado pela paisagem natural. Esses homens comentam a visão fugidia dos seres divinos. Um deles pergunta: "É verdade que os viram?". O outro responde: "O incrível relevo das coisas no ar ainda hoje comove o coração. Quanto a mim, creio que uma árvore, uma pedra recortada no céu foram deuses desde o início". ${ }^{20}$

Nos lugares incultos e solitários, como este em que os dois homens dialogam, o que mais poderia ser buscado senão o encontro com os deuses? Trata-se de uma experiência que os interlocutores consideram perdida, uma "outra coisa" que não o pão, nem o prazer, nem a saúde, algo antes conhecido pela humanidade: o plano mítico, a relação religiosa com o mundo natural e com o destino. A fala final que define o que foi perdido é: "Aqueles encontros com eles", "Quei loro incontri", nome que Straub escolheu para o filme.

Ao analisar a poética de Pavese, Ítalo Calvino afirma que se trata de "[...] chegar, por meio de uma árdua via de exclusões e reduções, até imagens que sejam nódulos de experiência insubstituíveis, comunicações absolutas em todos os níveis". ${ }^{21}$ Essa definição é perfeita para caracterizar o que fez Straub ao adaptar o livro do escritor italiano. Um exemplo disso é a simplicidade com que o tema do afastamento dos deuses é reforçado por uma última cena, na qual o movimento de elevação da câmera iniciado no plano aberto de uma vila se interrompe quando o enquadramento mostra um fio (elétrico ou de telefone) dividir a imagem: embaixo, a montanha ao longe dá início ao ambiente habitado pelos homens; acima da linha, o céu. Depois de todos os diálogos, essa cena final transcorre em silêncio. 
Como afirmou numa entrevista, Straub pretende trabalhar "com as palavras mais simples - e o menor número de palavras possível". Sua linguagem cinematográfica, extremamente econômica, reduzida a pouquíssimos gestos, aos elementos mínimos da ação, apresenta justamente uma poesia da austeridade e da simplicidade como a de Pavese em Diálogos com Leucó. Tanto no livro quanto no filme que o traduz para o cinema, não há nenhum desperdício. A tradução, ou adaptação, encontra uma forma única, muito própria, cuja austeridade e simplicidade desconcertantes visam fazer o espectador ver com um olhar novo as coisas que já viu e, ao mesmo tempo, dar densidade ao discurso, fazer cada palavra ressoar com a riqueza paradoxal de seu sentido.

\section{* Pedro Süssekind é professor adjunto de filosofia da UFOP.}

1 Entrevista citada no artigo de Ruy Gardnier "Homenagem a Danièle Huillet (e Jean-Marie Straub)", publicado na revista de cinema Contracampo 84, em janeiro de 2007.

2 Ibidem.

${ }^{3}$ Ver PAVESE, C. Diálogos com Leucó. São Paulo: Cosacnaify, 2001, p. 21.

${ }^{4}$ CALVINO, I. "Pavese: ser e fazer". In: PAVESE, C. Diálogos com Leucó. Op. cit., p. 220.

${ }^{5}$ Ver HÖLDERLIN, F. Sämtliche Werke und Briefe. Band 3. Berlim: Aufbau-Verlag, 1995, p. 394.

6 HÖLDERLIN, F. "Pão em vinho". Traduçãode José Paulo Paes. In: Poemas. São Paulo: Companhia das Letras, 1991, p. 169.

${ }^{7}$ Ibidem.

${ }^{8}$ PAVESE, C. Diálogos com Leucó. Op. cit, pp. 170-171.

9 Ibidem, p. 95.

10 Ibidem.

${ }^{11}$ Ibidem.

12 Ibidem.

${ }^{13}$ Ibidem.

${ }^{14}$ Ibidem, p. 186.

${ }^{15}$ Ibidem.

${ }^{16}$ Ibidem, p. 203.

${ }^{17}$ Ibidem.

${ }^{18}$ Ibidem.

${ }^{19}$ A esse respeito, ver SCHILLER, F. Poesia ingênua e sentimental. São Paulo: Iluminuras, 1991.

20 "Os deuses". In: Diálogos com Leucó. Op. cit., p. 208.

${ }^{21}$ CALVINO, I. "Pavese: ser e fazer", In: PAVESE, C. Op. cit., p. 213. 